\title{
Biodegradable Guar Gum Nanoparticles as Carrier for Tamoxifen Citrate in Treatment of Breast Cancer
}

\author{
Jayanta K. Sarmah ${ }^{1 *}$, Saibal Kanti Bhattacharjee², Samhita Roy ${ }^{3}$, Ranadeep Mahanta ${ }^{4}$, \\ Rita Mahanta ${ }^{3}$ \\ ${ }^{1}$ School of Engineering and Technology, Kaziranga University, Jorhat, India \\ ${ }^{2}$ Department of Chemistry, Gauhati University, Guwahati, India \\ ${ }^{3}$ Department of Zoology, Cotton College, Guwahati, India \\ ${ }^{4}$ Department of Biochemistry, Jorhat Medical College, Jorhat, India \\ Email: *jayanta@kazirangauniversity.in
}

Received 8 July 2014; revised 6 September 2014; accepted 19 September 2014

Copyright (C) 2014 by authors and Scientific Research Publishing Inc.

This work is licensed under the Creative Commons Attribution International License (CC BY).

http://creativecommons.org/licenses/by/4.0/

c) (i) Open Access

\begin{abstract}
We prepared, characterized and studied the biodistribution of tamoxifen citrate (TMX) loaded cross-linked guar gum (GG) nanoparticles (NPs). NPs were prepared via a single step emulsion process and particle size evaluated. The extent of tissue distribution and retention following oral administration of TMX loaded GG NPs and TMX tablet in female albino mice was analyzed over a period of 48 hours. Till 48 hours, the particles remained detectable in both mammary and ovary tissue (estrogen receptors). Uptake and retention of TMX from NPs and tablet in mammary gland and ovary tissue changed with time. Results showed that the uptake and retention of NPs was more in the mammary gland between $24-48$ hours (11.2\% at $24 \mathrm{~h} ; 4.65 \%$ at $48 \mathrm{~h})$. As mammary gland is the target organ in breast cancer therapy, it may be concluded that the cross-linked GG NPs are capable of releasing the drug at the target and minimize the uptake and retention in non target tissue, the ovary (7.98\% at $24 \mathrm{~h} ; 1.9 \%$ at $48 \mathrm{~h})$. Serum alanine aminotransferase (ALT) and aspartate aminotransferase (AST) with time were measured. No abnormal changes in the liver enzymes were observed. GG NPs under study can be used as a drug carrier system for treating cancer.
\end{abstract}

\section{Keywords}

Tamoxifen Citrate, Guar Gum, Nanoparticles, ER(+) Tumors, Biodistribution

\footnotetext{
${ }^{*}$ Corresponding author.
}

How to cite this paper: Sarmah, J.K., Bhattacharjee, S.K., Roy, S., Mahanta, R. and Mahanta, R., (2014) Biodegradable Guar Gum Nanoparticles as Carrier for Tamoxifen Citrate in Treatment of Breast Cancer. Journal of Biomaterials and Nanobiotechnology, 5, 220-228. http://dx.doi.org/10.4236/jbnb.2014.54026 


\section{Introduction}

"Cancer", one of the major cases of death worldwide with lung, stomach, liver, colon and breast cancers is expected to increase the death rate from 7.9 million in 2007 to 11.5 million in 2030 [1]. The major problem is the severe toxic side effects of anticancer drugs on healthy tissues. These side effects in turn impose dose reduction, treatment delay or discontinuance of therapy. Also most of the anticancer drugs are receptor specific but possess limitations in their delivery [2], because often the molecules have a high molecular weight and are water insoluble and have a short half life. As a result these drugs exhibit a poor oral bioavailability, unfavorable pharmacokinetic profile etc. An attractive strategy to enhance the therapeutic index of drugs is to specifically deliver these agents to the defined target cells thus keeping them away from healthy cells which are sensitive to the toxic effects of the drug. While doing so the pharmaceutical industry is faced with the challenge of introducing new drug delivery systems with reliable performance but also with a greater emphasis on patient compliance [3]-[4]. These challenges of drug development go through successive stages, such as, design of suitable delivery systems and in vivo evaluation [5]-[7]. The efficacy of presently available promising anticancer agents like tamoxifen citrate, doxorubicin, paclitaxel is limited by toxic side effects due to non-specific distribution, especially to the rapidly proliferating cells in body. Also, limitations result from the fact that these agents fail to selectively localize in tumors, which emphasizes the need for new drug delivery systems. To suppress toxic effects and to improve efficacy numerous delivery systems based on specific carrier properties are being extensively studied and evaluated in the field of cancer chemotherapeutics [8]-[11].

Polysaccharides, the polymers of monosaccharides (sugars) are found in abundance, have wide availability, are inexpensive and available in a variety of structures with a variety of properties. They can be easily modified chemically and biochemically and are highly stable, safe, nontoxic, hydrophilic and gel forming and in addition are biodegradable. Due to their excellent inherent properties natural polysaccharides are now extensively used for the development of carrier systems for delivery of anticancer drugs [12].

Tamoxifen citrate, a non-steroid antiestrogen, is the endocrine treatment modality most widely used in breast cancer [13]. Antiestrogen therapy principally affects estrogen receptor (ER)-rich tissues. Tamoxifen, the prototypical antiestrogen, has been employed over the course of three decades for the treatment of ER(+) tumors [14]. It is a selective estrogen response modifier (SERM) [15] that exerts antagonistic effects in breast cancer cells and agonistic effects in other tissues, such as endometrium and bone. This non-streoid compound and its reactive intermediates increase the risk of endometrial and uterine cancer in breast cancer patients receiving tamoxifen therapy [16] and its estrogenic action provides a protective effect against osteoporosis and cardiovascular disease [17].

In this context, we synthesized TMX loaded nanoparticles with satisfactory drug loading content (>15\%) by a novel single step emulsion in-situ polymer cross-linking method. Guar gum, a biocompatible, biodegradable, non-toxic, readily available and low cost natural polysaccharide was used as the polymer material of the nanoparticles [18]-[21]. Although guar gum has been formulated in both matrix tablet and microspheres in the past but only little information is available in the open literature for the possibility of using guar gum based nanosized materials as a drug carrier [18] [20].

To assess the applicability of the prepared drug loaded nanoparticles in a biological system for prospective therapeutic use as a drug delivery agent in the present investigation, a model experiment was designed with female albino mice as the biological system, drug formulated nanoparticles as the drug delivery agent into the system and mammary and ovary tissues as the target locations. This whole experiment was done against a control set receiving free TMX and compared with a set of the same drug in tablet preparation.

\section{Materials and Methods}

Tamoxifen Citrate was a gift from Central Drugs Laboratory, Kolkata, India. Nolvadex tablets were purchased locally. All other chemicals were purchased from Rankem (India) Ltd. Millipore water was used in nanoparticle preparation.

\subsection{Nanoparticle Preparation}

Nanoparticles of guar gum containing tamoxifen citrate were prepared with the optimized formulation condition: 1:6 drug:polymer ratio, $0.5 \%(\mathrm{~m} / \mathrm{V})$ guar gum concentration, $10 \mathrm{ml}$ glycerol as stabilizer, $2 \mathrm{ml}(3 \%)$ glutaralde- 
hyde (GTA) solution as crosslinker and dichloromethane as the drug loading solvent [22] [23]. Prepared nanoparticles were harvested in microcentrifuge tubes and preserved in vacuum desiccator till use.

\subsection{Particle Size}

Particle size was evaluated by dynamic light scattering measurements using a Malvern Zetasizer Nano ZS (Malvern Instruments, Worcestershire, United Kingdom) with a $10 \mathrm{~mW}$ He-Ne laser beam at $20^{\circ} \mathrm{C}$. A scattering angle of $90^{\circ}$ was used. Before DLS analysis, the TMX loaded NPs were dispersed in aqueous buffer, then sonicated for a few minutes, filtered through 0.2-micron pore size filtration unit (Millipore, Billerica, MA, U.S.A.). The sample concentration was kept at $1.0 \mathrm{mg} / \mathrm{ml}$. Each sample was measured in triplicate.

\subsection{Size Distribution in TEM}

Transmission electron microscopy (FEI Technai 12 Bio Twin, The Netherlands) with a CCD camera mega view II soft imaging system was employed to visualize and record the nature and the size distribution of NPs. A drop of water suspension of the GG NPs was mounted on a carbon coated copper grid (CCG) and air-dried and micro graphed at $80-100 \mathrm{kV}$.

\subsection{In-Vivo Studies}

Female albino mice (25 - 30 g) were used in this experiment. The animals bred at Department of Zoology, Gauhati University, Guwahati, Assam, India was procured after obtaining clearance from the Animal Ethics Committee of Gauhati University. Before the experimental procedure was started, all the animals were acclimatized in the animal room for four weeks and fed on standard animal diet. All of the procedures complied with the guidelines of International Animal Ethics Committee. The animals were orally administered with a single dose of free TMX, NPs ( $5 \mathrm{mg} / \mathrm{Kg}$ body weight) and TMX tablet formulation ( $5 \mathrm{mg} / \mathrm{Kg}$ body weight) for comparison. The mice were anaesthetized by diethyl ether and dissected to collect the tissues. The animals were sacrificed after an interval of 6, 12, 24 and 48 hours for collection of blood and tissue samples. Blood samples were drawn by cardiac puncture with all aseptic and antiseptic measures and collected in a microcentrifuge tube for seperation of serum.

\subsubsection{Analysis of Serum}

Blood samples were allowed to clot at room temperature and centrifuged at $3000 \mathrm{rpm}$ for $10 \mathrm{~min}$ to separate the serum for collection. The supernatant serum was then transferred into a dry labeled and stoppered micro centrifuge tube and immediately used for analysis of ALT and AST levels.

\subsubsection{Analysis of Tissue}

The mice were anaesthetized by diethyl ether and dissected to collect the tissues from mammary gland and ovary. The tissues were dried over a filter paper and immediately weighted and recorded. The tissue homogenate was prepared in $2 \mathrm{ml}$ buffer solution with a morter in an ice bath. The total volume of each homogenate was measured. The homogenate was transferred into microcentrifuge tubes and centrifuged for 5 minutes at 3000 $\mathrm{rpm}$. The supernatent was carefully collected and preserved in dry labeled and stoppered micro centrifuge tubes and stored at $2^{\circ} \mathrm{C}$ to $8^{\circ} \mathrm{C}$. Tissue homogenates were used to estimate the TMX content (\%) in respective tissues by high performance liquid chromatography (HPLC) analysis. $100 \mu$ l tissue homogenate were transferred by a micropipette to a microcentrifuge tube containing $1 \mathrm{ml}$ chloroform and $0.5 \mathrm{ml} 6 \%$ perchloric acid. The mixture was vortexed and centrifuged. A $20 \mu \mathrm{l}$ volume of the supernatent of each sample was injected through rheodyne injector port of the standardized HPLC system for estimation of TMX concentration. The HPLC method was validated intra day and intra night for TMX prior to start of analysis.

\subsection{Toxicity Evaluation}

Just before the start of this evaluation the animals were sacrificed and blood was collected by cardiac puncture. Liver toxicity markers ALT and AST were estimated by the commercially available diagnostic kits (Crest Biosystems, manufactured by Coral Clinical Systems, India). AST and ALT results were expressed as mean \pm S.D. Significant differences amount the groups were determined by one-way analyses of variance (ANOVA) fol- 
lowed by student t-test using the statistical analysis software (SPSS). Statistical significance was considered at p $<0.05$.

The kit procedure was based on the methodology of the International Federation of Clinical Chemistry (IFCC) and the method was Modified IFCC Method, The activity was assayed by UV kinetic method and calculated as in Equation (1).

$$
\text { AST/ALT activity in } \mathrm{U} / \mathrm{L}=\text { Change of absorbance per minute at } 340 \mathrm{~nm} \times \text { factor }(8840)
$$

Linearity: AST/ALT activity kit is linear up to $350 \mathrm{U} / \mathrm{L}$.

\section{Results}

Tamoxifen citrate loaded guar gum nanoparticles were prepared with optimized formulation condition: 1:6 drug: polymer ratio, $0.5 \%(\mathrm{~m} / \mathrm{V})$ guar gum concentration, $10 \mathrm{ml}$ glycerol as stabilizer, $2 \mathrm{ml}$ (3\%) glutaraldehyde (GTA) solution as crosslinker and dichloromethane as the drug loading solvent with a loading of $15 \%$ of the drug.

The size of the NPs as measured by DLS showed a narrow size distribution (200 - $300 \mathrm{~nm}$, Figure 1(a)). TEM study revealed smooth and spherical nanoparticles with an average size of $205 \mathrm{~nm}$ (Figure 1(b)).

\subsection{Biodistribution of TMX}

TMX and TMX loaded NPs were administered orally into female albino mice to study the biodistribution in mammary and ovary tissue and cytotoxicity on liver enzyme functions.

Uptake and retention of TMX from NPs varied in both mammary gland and ovary tissue (Table 1(b) and Figures 2(a)-(d)). TMX levels in the mammary gland 6 hrs after administration was found to be $1.3 \%$ of the total administered dose which then gradually increased to $7.08 \%$ at $12 \mathrm{hrs}, 11.2 \%$ at 24 hrs and $4.65 \%$ at 48 hrs. TMX levels in the ovary tissue $6 \mathrm{~h}$ after administration was found to be $6.66 \%$ of the total administered dose which then gradually increased to $7.62 \%$ at 12 hrs, $7.98 \%$ at 24 hrs and $1.9 \%$ at 48 hrs (Figures 2(a)).

Uptake and retention of TMX from tablet also varied in both mammary gland and ovary tissue. TMX levels in the mammary gland $6 \mathrm{~h}$ after tablet administration was found to be $7.6 \%$ of the total administered dose which then gradually increased to $9.48 \%$ at $12 \mathrm{hrs}$ and then declined to $6.56 \%$ at $24 \mathrm{hrs}$ and $2.34 \%$ at $48 \mathrm{hrs}$. TMX levels in the ovary tissue $6 \mathrm{~h}$ after administration was found to be $7.88 \%$ of the total administered dose which then gradually increased to $10.02 \%$ at 12 hrs and then decreased to $6.88 \%$ at 24 hrs and $2.14 \%$ at 48 hrs (Figure 2(b)).

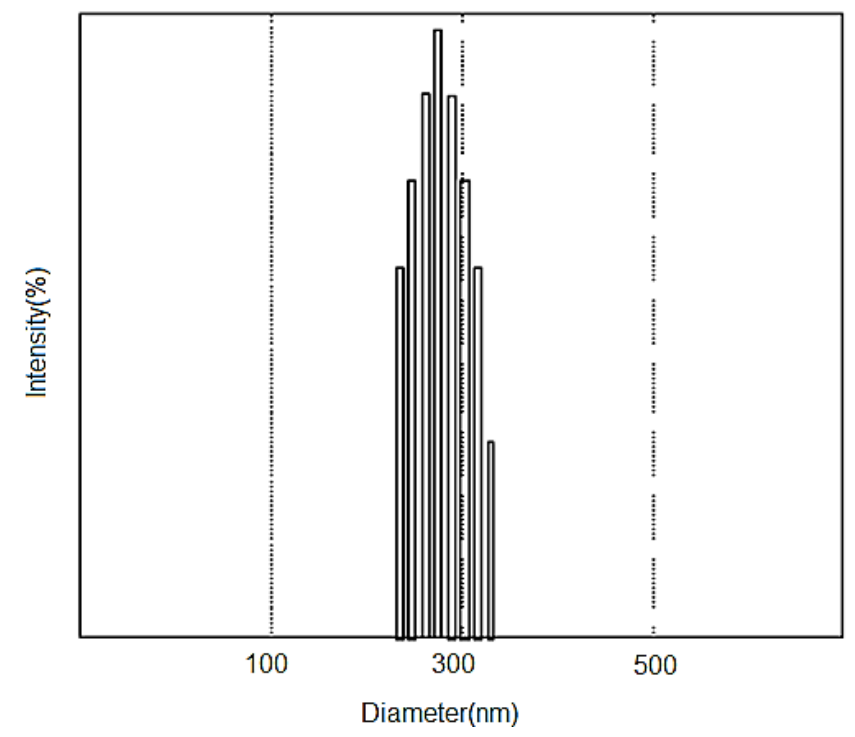

(a)

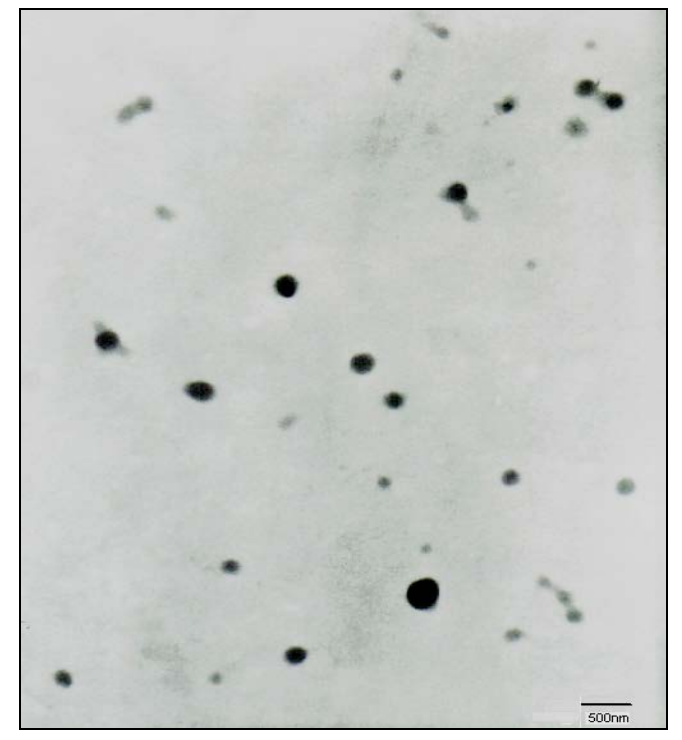

(b)

Figure 1. (a) Particle size of TMX loaded GG NPs; (b) TEM micrograph of TMX loaded guar gum nanoparticles showing particle distribution pattern. 


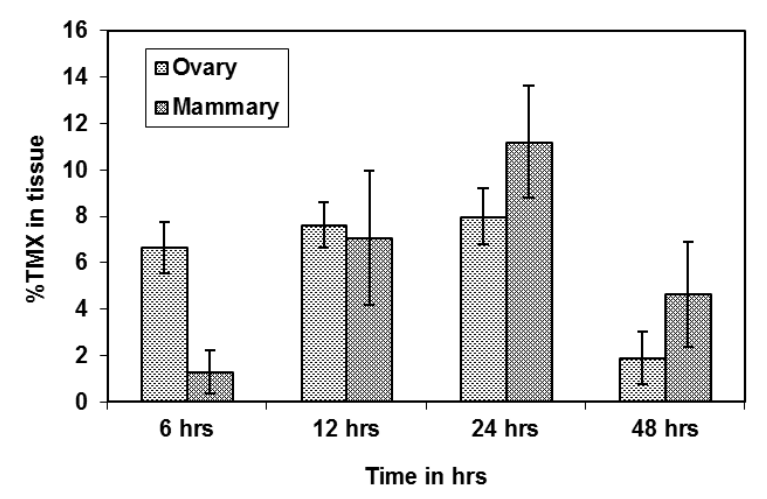

(a)

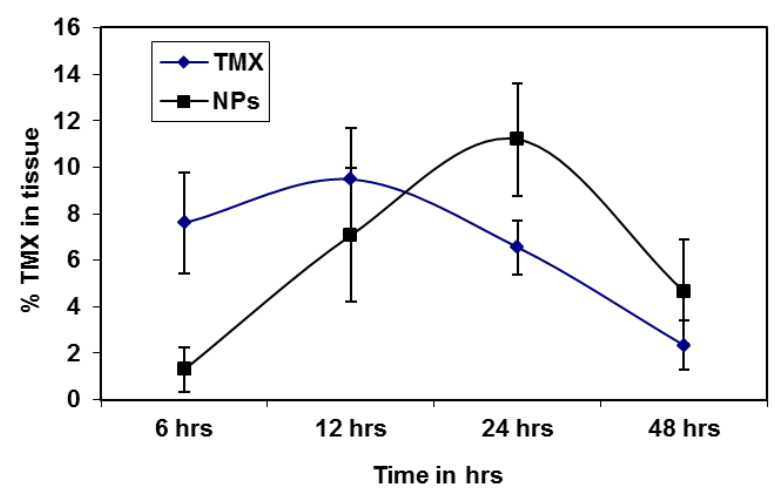

(c)

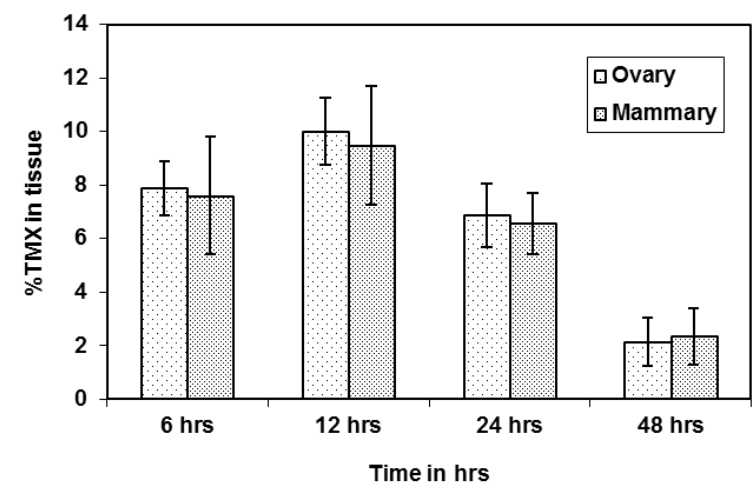

(b)

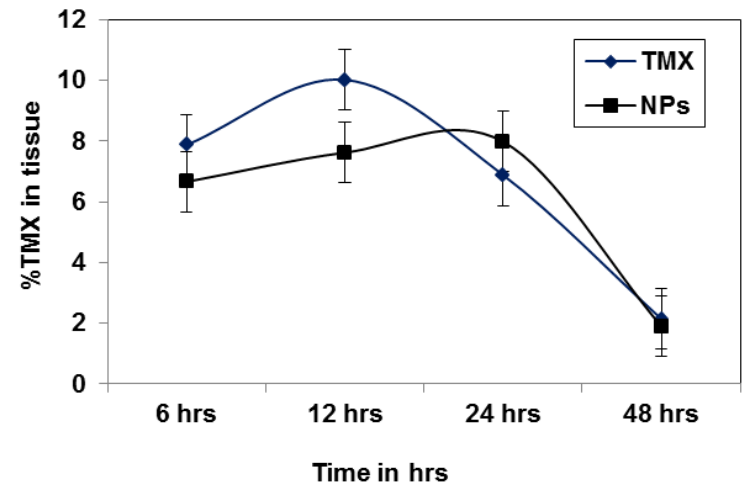

(d)

Figure 2. (a)-(b) Comparative biodistribution of TMX in ovary and mammary tissue of mice after NPs and tablet administration; (c)-(d) Comparative biodistribution of TMX in mammary gland and ovary tissue of mice after tablet and NPs administration.

Table 1. (a) (b) Mean TMX uptake at different time intervals in ovary and mammary tissue in \% of single dose of oral administration of TMX in tablet ( $5 \mathrm{mg} / \mathrm{Kg}$ body wt.) to female albino mice.

(a)

\begin{tabular}{ccccc}
\hline Organ/tissue & \multicolumn{4}{c}{ Mean\% TMX uptake in tissues at different time interval } \\
\hline & 6 hrs & 12 hrs & 24 hrs & 48 hrs \\
\hline Ov drug & 7.88 & $\%$ drug & 10.02 & $\%$ drug drug \\
\hline SD & 1.01 & 1.25 & 6.88 & 2.14 \\
Mammary & 7.61 & 9.48 & 1.19 & 0.91 \\
SD & 2.19 & 2.2 & 6.56 & 1.16 \\
\hline
\end{tabular}

(b)

\begin{tabular}{|c|c|c|c|c|}
\hline \multirow[t]{2}{*}{ Organ/tissue } & \multicolumn{4}{|c|}{ Mean\% TMX uptake in tissues at different time interval } \\
\hline & $6 \mathrm{hrs}$ & $12 \mathrm{hrs}$ & $24 \mathrm{hrs}$ & $48 \mathrm{hrs}$ \\
\hline & $\%$ drug & $\%$ drug & $\%$ drug & $\%$ drug \\
\hline Ovary & 6.66 & 7.62 & 7.98 & 1.9 \\
\hline $\mathrm{SD}$ & 1.11 & 0.98 & 1.2 & 1.12 \\
\hline Mammary & 1.3 & 7.08 & 11.2 & 4.65 \\
\hline $\mathrm{SD}$ & 0.95 & 2.87 & 2.42 & 2.85 \\
\hline
\end{tabular}




\subsection{Toxicity Evaluations}

Changes in the serum AST and ALT levels are commonly used as biochemical markers for liver function. Enzyme activities were studied at 6, 12, 24 and 48 hrs after oral administration of NPs, TMX tablet and free TMX. TMX loaded GG NPs showed a reduction in hepatoxicity as compared to free TMX and TMX tablet. AST, ALT levels in serum are normally increased in case of hepatotoxicity. As observed in (Figure 3(a) \& Figure 3(b)), the levels of these markers increased significantly in the case of TMX $(\mathrm{p}<0.05)$ given orally while no significant ( $p>0.05)$ increase was observed in the case of TMX loaded GG NPs.

\section{Discussion}

Biodistribution, biodegradability, long circulation and toxicity has been the key issues of most of the carrier system. Polymeric nanoparticles composed of synthetic and semi synthetic polymers suffers from toxicity, low drug loading capacity and the drug is released within few hours after administration before reaching the target. These factors limit the applications of polymeric NPs as drug-carrier systems. We prepared nanoparticles of guar gum, a non toxic natural polymer containing tamoxifen citrate. Guar gum NPs can be loaded with a fair amount of the drug and the loaded drug is released over a period of $48 \mathrm{~h}$ and shows tissue specific biodistribution.

From the biodistribution results it is evident that when TMX level in mammary tissue $6 \mathrm{~h}$ after NPs administration was $1.3 \%$, ovary TMX level was $6.66 \%$. Initially a higher concentration of the drug was found at the ovary tissue but with time the mammary TMX levels increased to $11.2 \%$ at $24 \mathrm{~h}$ after administration than $7.98 \%$ in the ovary (Figure 2(a)). Mammary gland is the target organ of breast cancer treatment. The object of the present study was to study the drug levels in the target and non target tissue. As seen from the observed data that with prolonged time TMX levels in target tissue i.e. mammary, increased compared to the non-target tissue i.e. ovary, of our study. It was also observed that in case of NPs administered group the TMX level in both mammary and ovary was maximum at $24 \mathrm{~h}$ after administration (Figure 2(a)).

Also for the TMX tablet administered group, mammary TMX level was $9.48 \%$ at $12 \mathrm{~h}$ compared to $10.02 \%$ of ovary TMX level at $12 \mathrm{~h}$ after administration (Figure 2(b)). As seen from the observed data that with time TMX levels in target tissue i.e. mammary and non-target tissue i.e. ovary remained more or less the same (Figure 2(b)). The mammary and ovary TMX level in both the tissues were maximum at $12 \mathrm{~h}$ after administration (Figure 2(b)). There is a clear difference in the biodistribution of TMX loaded GG NPs than the TMX in tablet formulation in both mammary and ovary tissue of female albino mice (Figure 2(a) \& Figure 2(b)).

Estrogen receptors (ERs) exist in the liver, lungs, breast, ovary, uterus, brain, heart and bone tissues and antiestrogen therapy of TMX principally affects these estrogen receptor (ER)-rich tissues [13]. On comparison of the results of biodistribution from both the formulation of drug in the present study it is observed that, till $12 \mathrm{hrs}$ after administration the maximum uptake and retention of the drug from both the tablet and NPs was found in ovary tissue which is the non target organ of the present investigation (Figure 2(d)). However at 24 and 48 hrs after administration the comparison of both the formulation exhibited a reverse trend to each other (Figure 2(c) \& Figure 2(d)). While the uptake and retention of TMX from the tablet formulation remained maximum at ovary at 24 hrs, on the contrary the uptake and retention of TMX from NPs remained maximum at the mammary gland. The significantly high concentration of the drug in mammary gland at 24 and 48 hrs after NPs administration clearly indicates the targeting ability of the prepared drug loaded guar gum nanoparticles. Thus it may be assumed that these nanoparticles might become a promising high-performance delivery system for TMX for treatment of breast cancer.

Guar gum and similar polysaccharides retain their integrity because they are resistant to the digestive action of gastrointestinal enzymes. This family of natural polymers has an appeal to the area of drug delivery as it is comprised of polymers with a large number of derivatizable groups, a wide range of molecular weights, varying chemical compositions, and for the most part, a low toxicity and biodegradability, yet a high stability. The most favorable property of these materials is that they are already approved as pharmaceutical excipients. As these polysaccharides are usually soluble in water, they must be made water insoluble by crosslinking or hydrophobic derivatisation. Cross-linking of the guar gum with glutaraldehyde reduces water uptake of nanoparticles which in turn reduces swelling behaviour of guar gum in aqueous media [24]-[26]. High and superior mammary TMX level at extended time intervals may be attributed to this cross-linking effect of the NPs. Our work is in good agreement with earlier findings [27]. 


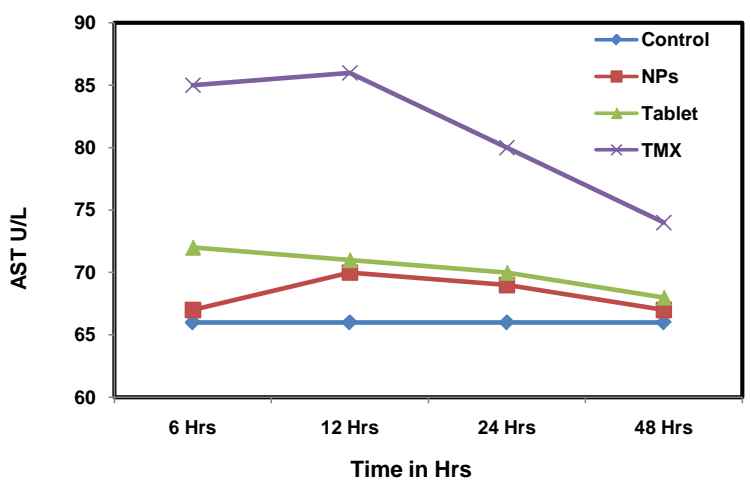

(a)

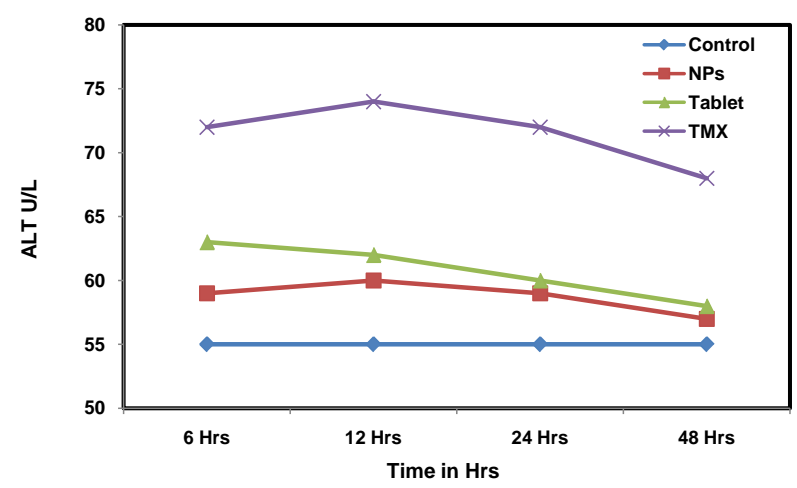

(b)

Figure 3. (a)-(b) Serum AST and ALT levels at different time intervals.

The significantly higher concentrations of the drug loaded GG NPs reaching the mammary gland at 24 hrs and 48 hrs post administration compared with TMX tablet suggests sustained release of the drug from the nanocarrier in-vivo as well as the present findings may suggest the reduced toxic effects of NPs on non targeted ER positive tissue.

There is known evidences in the literature that TMX increases some hepatotoxicity markers levels like ALT and AST in the plasma as well as in liver homogenate [28] [29]. AST and ALT level were not significantly increased ( $p>0.05$ ) when TMX loaded GG NPs were administered orally for 48 hrs compared to the control group without receiving any dose whereas these levels increased for free TMX administered in similar manner as observed from Figure 3(a) \& Figure 3(b). The increased hepatotoxicity marker levels for TMX could be attributed to oxidative reactions that take place during its metabolism in the liver [30] [31]. It may be assumed that the decreased hepatotoxicty of TMX after the encapsulation in GG NPs could be due to its ability to escape from first pass metabolism in the liver.

The observations of insignificance differences with the serum AST and ALT activity from the control group in the present investigation grossly suggest that with the doses administered under the present experimental conditions of both the NPs and TMX tablet do not have any significant cytotoxic effect on liver which is the primary organ for detoxification of drugs and genobiotic substances.

Based on the results from this study, it might be possible that nanoparticle will enhance retention time and amount of TMX in the tumors since a tumor in the body also behaves as an organ with blood supplies. Thus, the present study represents the first step in exploring the potential of guar gum nanoparticles as TMX-delivery system for use in tumor-diagnosis. Uptake and retention of TMX is under investigation with tumor-bearing animal models and a cell line study with MCF7 cells is in process to evaluate the in-vitro cytotoxicity and sustained nature of the GG NPs.

\section{Conclusion}

Nanoparticles by virtue of its size and properties are potential tools for treating cancer. Guar gum nanoparticles containing tamoxifen citrate under the present investigation exhibited the benefits of nanoencapsulation for highly protein binding drug tamoxifen citrate in passive targeting of cancer. The drug loaded nanoparticles provided superior biodistribution in mammary tissue which is the target organ in breast cancer treatment.

\section{Competing Interests}

The authors declare no conflict of interest.

\section{References}

[1] www.who.int/topics/cancer/

[2] Rabinow, B.E. (2004) Nanosuspensions in Drug Delivery. Nature Reviews Drug Discovery, 39, 785-796. http://dx.doi.org/10.1038/nrd1494

[3] Meibohm, B. and Derendorf, H. (2002) Pharmacokinetic/Pharmacodynamic Studies in Drug Product Development. 
Journal of Pharmaceutical Sciences, 91, 18-31. http://dx.doi.org/10.1002/jps.1167

[4] Scaglione, F. (2002) Can PK/PD Be Used in Everyday Clinical Practice. International Journal of Antimicrobial Agents, 19, 349-353. http://dx.doi.org/10.1016/S0924-8579(02)00020-1

[5] Duncan, R., Coatsworth, J.K. and Burtles, S. (1998) Preclinical Toxicology of a Novel Polymeric Antitumour Agent: HPMA Copolymer-Doxorubicin (PK1). Human \& Experimental Toxicology, 17, 93-104. http://dx.doi.org/10.1191/096032798678908378

[6] Hopewel, J.W., Duncan, R., Wilding, D. and Chakrabarti, K. (2001) Preclinical Evaluation of the Cardiotoxicity of PK2: A Novel HPMA Copolymer-Doxorubicin-Galactosamine Conjugate Antitumour Agent. Human \& Experimental Toxicology, 20, 461-470. http://dx.doi.org/10.1191/096032701682693017

[7] Mahmood, I. (2001) Interspecies Scaling of Maximum Tolerated Dose of Anticancer Drugs: Relevance to Starting Dose for Phase I Clinical Trials. American Journal of Therapeutics, 8, 109-116. http://dx.doi.org/10.1097/00045391-200103000-00005

[8] Howell, S.B. (2001) Clinical Applications of a Novel Sustained-Release Injectable Drug Delivery System: DepoFoam Technology. Cancer Journal, 7, 219-227.

[9] Maeda, H. (2001) The Enhanced Permeability and Retention (EPR) Effect in Tumor Vasculature: The Key Role of Tumor-Selective Macromolecular Drug Targeting. Advances in Enzyme Regulation, 41, 189-207. http://dx.doi.org/10.1016/S0065-2571(00)00013-3

[10] Park, J.W. (2002) Liposome Based Drug Delivery in Breast Cancer Treatment. Breast Cancer Research, 4, 95-99. http://dx.doi.org/10.1186/bcr432

[11] Goldenberg, D.M. (2002) Targeted Therapy of Cancer with Radiolabeled Antibodies. Journal of Nuclear Medicine, 43, 693-713.

[12] Schipper, N.G.M., Varum, K.M. and Artursson, P. (1996) Chitosan as Absorption Enhancers for Poorly Absorbable Drugs: Influence of Molecular Weight and Degree of Acetylation on Drug Transport across Human Intestinal Epithelia (Caco-29 Cells). Pharmaceutical Research, 13, 1686-1692. http://dx.doi.org/10.1023/A:1016444808000

[13] Martin, E.A., Brown, K., Gaskell, M., Al-Azzawi, F., Garner, R.C., Boocock, D.J., Mattock, E., Pring, D.W., Dingley, K., Turteltaub, K.W., Smith, L.L. and White, I.N.H. (2003) Tamoxifen DNA Damage Detected in Human Endometrium Using Accelerator Mass Spectrometry. Cancer Research, 63, 8461-8465.

[14] Lashley, M.R., Niedzinski, E.J., Rogers, J.M., Denison, M.S. and Nantz, M.H. (2002) Synthesis and Estrogen Receptor Affinity of a 4-Hydroxytamoxifen-Labeled Ligand for Diagnostic Imaging. Bioorganic \& Medicinal Chemistry, 10, 4075-4082. http://dx.doi.org/10.1016/S0968-0896(02)00329-2

[15] Marcsek, Z., Kocsis, Z., Jakab, M., Szende, B. and Tompa, A. (2004) The Efficacy of Tamoxifen in Estrogen ReceptorPositive Breast Cancer Cells Is Enhanced by a Medical Nutriment. Cancer Biotherapy \& Radiopharmaceuticals, 19, 746-753. http://dx.doi.org/10.1089/cbr.2004.19.746

[16] Heres-Pulido, E.M., Duenas-Garcia, I., Castaneda-Partida, L., Sanchez-Garcia, A., Contreras-Sousa, M., Duran-Dias, A. and Ulrich, G. (2004) Genotoxicity of Tamoxifen Citrate and 4-Nitroquinoline-1-Oxide in the Wing Spot Test Drosophila Melanogaster. Mutagenesis, 19, 187-193. http://dx.doi.org/10.1093/mutage/geh020

[17] Chodak, G.W. and Kolvenbag, G.J.C.M. (2001) Will the Experience with Tamoxifen in Breast Cancer Help Define the Role of Antiandrogens in Prostate Cancer? Prostate Cancer and Prostatic Diseases, 4, 72-80. http://dx.doi.org/10.1038/sj.pcan.4500518

[18] Krishnaiah, Y.S.R., Karthikeyan, R.S. and Satyanarayana, V. (2002) A Three-Layer Guar Gum Matrix Tablet for Oral Controlled Delivery of Highly Soluble Metoprolol Tartrate. International Journal of Pharmaceutics, 241, 353-366. http://dx.doi.org/10.1016/S0378-5173(02)00273-9

[19] Toti, U.S. and Aminabhavi, T.M. (2004) Modified Guar Gum Matrix Tablet for Controlled Release of Diltiazem Hydrochloride. Journal of Controlled Release, 95, 567-577. http://dx.doi.org/10.1016/j.jconrel.2003.12.019

[20] Soppirnath, K.S. and Aminabhavi, T.M. (2002) Water Transport and Drug Release Study from Cross-Linked Polyacrylamide Grafted Guar Gum Hydrogel Microspheres for the Controlled Release Application. European Journal of Pharmaceutics and Biopharmaceutics, 53, 87-98. http://dx.doi.org/10.1016/S0939-6411(01)00205-3

[21] Wassel, G.M., Omar, S.M. and Ammar, N.M. (1989) Application of Guar Flour and Prepared Guaran in Tablet Manufacture. Journal of Drug Research, 18, 1-8.

[22] Sarmah, J.K., Mahanta, R., Bhattacharjee, S.K., Mahanta, R. and Biswas, A. (2011) Controlled Release of Tamoxifen Citrate Encapsulated in Cross-Linked Guar Gum Nanoparticles. International Journal of Biological Macromolecules, 49, 390-396. http://dx.doi.org/10.1016/j.ijbiomac.2011.05.020

[23] Sarmah, J.K., Bhattacharjee, S.K., Mahanta, R. and Mahanta, R. (2009) Preparation of Cross-Linked Guar Gum Nanospheres Containing Tamoxifen Citrate by Single Step Emulsion in Situ Polymer Cross-Linking Method. Journal of 
Inclusion Phenomena and Macrocyclic Chemistry, 65, 329-334.

[24] Gliko-Kabir, I., Yagen, B., Penhasi, A. and Rubinstein, A. (2000) Phosphated Crosslinked Guar for Colon-Specific Drug Delivery: I. Preparation and Physicochemical Characterization. Journal of Controlled Release, 63, 121-127. http://dx.doi.org/10.1016/S0168-3659(99)00179-0

[25] Gliko-Kabir, I., Yagen, B., Penhasi, A. and Rubinstein, A. (1998) Low Swelling, Crosslinked Guar and Its Potential Use as Colon-Specific Drug Carrier. Pharmaceutical Research, 15, 1019-1025. http://dx.doi.org/10.1023/A:1011921925745

[26] Krishnaiah, Y.S.R., Seetha Devi, A., Nageswara Rao, L., Bhaskar Reddy, P.R., Karthikeyan, R.S. and Satyanarayana, V. (2001) Guar Gum as a Carrier for Colon Specific Delivery; Influence of Metronidazole and Tinidazole on in Vitro Release of Albendazole from Guar Gum Matrix Tablets. Journal of Pharmacy and Pharmaceutical Sciences, 4, 235243.

[27] Gliko-Kabir, I., Yagen, B., Baluom, M. and Rubinstein, A. (2000) Phosphated Crosslinked Guar for Colon-Specific Drug Delivery. II. In Vitro and in Vivo Evaluation in the Rat. Journal of Controlled Release, 63, 129-134. http://dx.doi.org/10.1016/S0168-3659(99)00180-7

[28] Hard, G.C., Iatropoulos, M.J., Jordan, K., Radi, L., Kaltenberg, O.P., Imondi, A.R. and Williams, G.M. (1993) Major Difference in the Hepatocarcinogenicity and DNA Adduct Forming Ability between Toremifene and Tamoxifen in Female Crl: CD (BR) Rats. Cancer Research, 53, 4534-4541.

[29] Albukhari, A.A., Gashlan, H.M., El-Beshbishy, H.A., Nagy, A.A. and Abdel-Naim, A.B. (2009) Caffeic Acid Phenethyl Ester Protects against Tamoxifen-Induced Hepatotoxicity in Rats. Food and Chemical Toxicology, 47, 1689-1695. http://dx.doi.org/10.1016/j.fct.2009.04.021

[30] Elefsiniotis, I.S., Pantazis, K.D., Ilias, A., Pallis, L., Mariolis, A., Glynou, I., Kada, H. and Moulakakis, A. (2004) Tamoxifen Induced Hepatotoxicity in Breast Cancer Patients with Pre-Existing Liver Steatosis: The Role of Glucose Intolerance. European Journal of Gastroenterology \& Hepatology, 16, 593-598. http://dx.doi.org/10.1097/00042737-200406000-00013

[31] Jain, A.K., Swarnakar, N.K., Godugu, C., Singh, R.P. and Jain, S. (2011) The Effect of the Oral Administration of Polymeric Nanoparticles on the Efficacy and Toxicity of Tamoxifen. Biomaterials, 32, 503-515.

http://dx.doi.org/10.1016/j.biomaterials.2010.09.037 
Scientific Research Publishing (SCIRP) is one of the largest Open Access journal publishers. It is currently publishing more than 200 open access, online, peer-reviewed journals covering a wide range of academic disciplines. SCIRP serves the worldwide academic communities and contributes to the progress and application of science with its publication.

Other selected journals from SCIRP are listed as below. Submit your manuscript to us via either submit@scirp.org or Online Submission Portal.
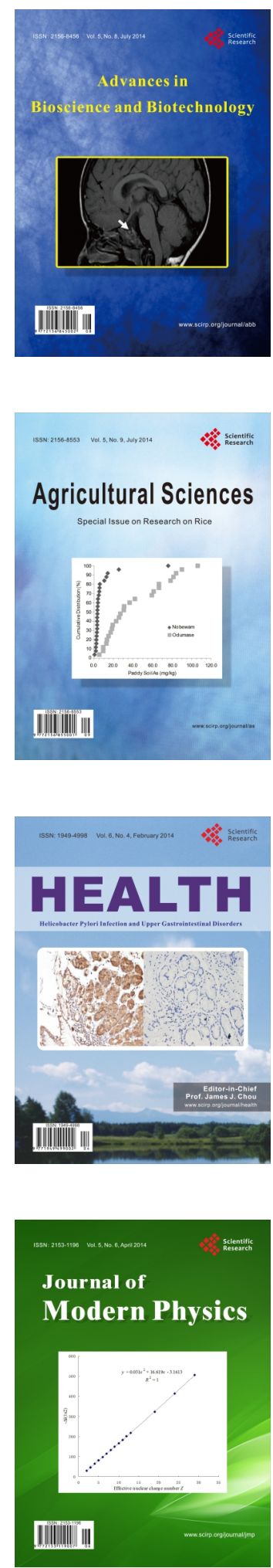
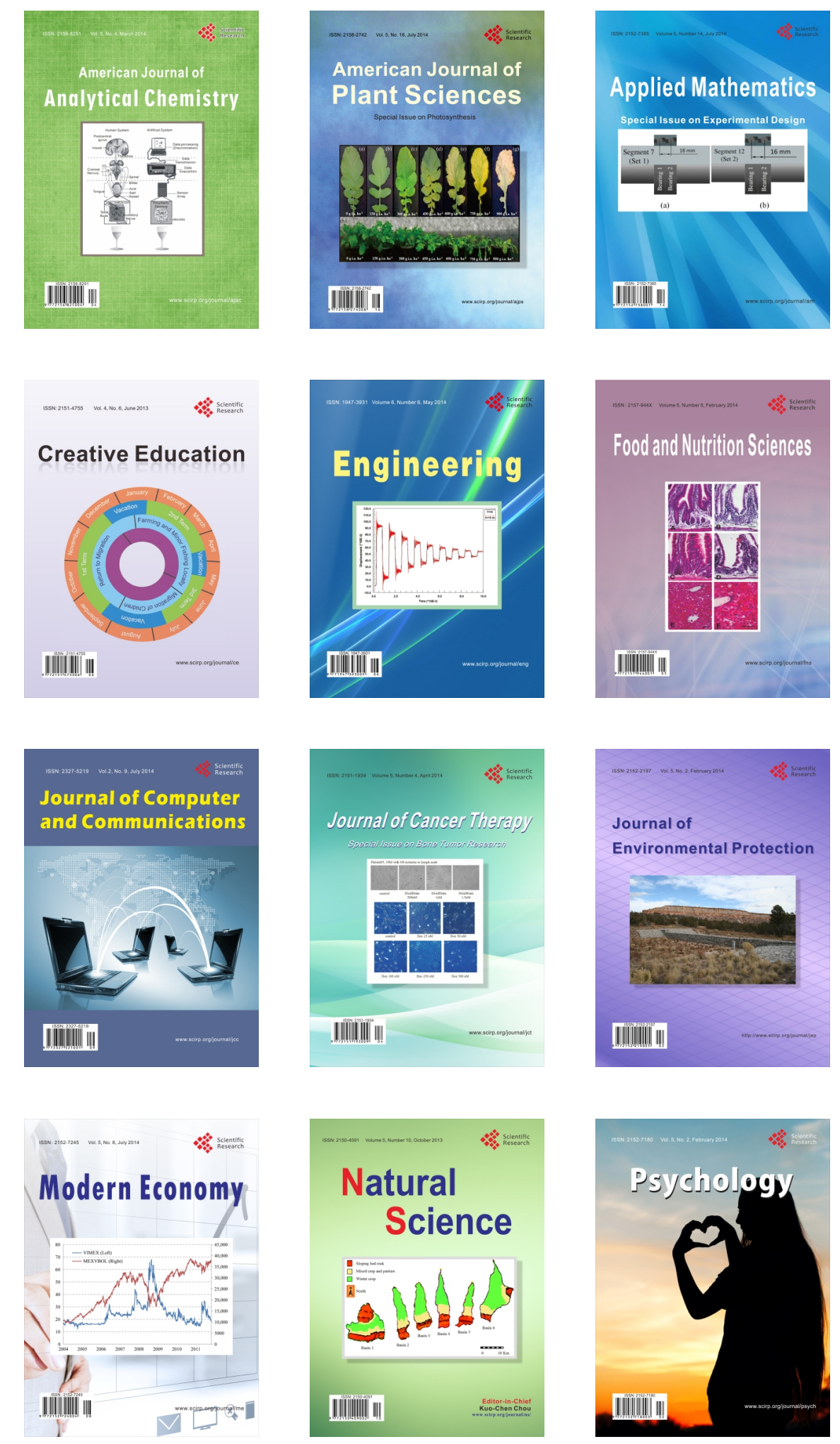